\title{
Pulmonary hypertension and pulmonary artery dissection ${ }^{*, * * *}$
}

\author{
Dissecção da artéria pulmonar e hipertensão pulmonar \\ Ricardo de Amorim Corrêa, Luciana Cristina dos Santos Silva, \\ Cláudia Juliana Rezende, Rodrigo Castro Bernardes, \\ Tarciane Aline Prata, Henrique Lima Silva
}

\begin{abstract}
Pulmonary artery dissection is a fatal complication of long-standing pulmonary hypertension, manifesting as acute, stabbing chest pain, progressive dyspnea, cardiogenic shock, or sudden death. 1ts incidence has been underestimated, and therapeutic options are still scarce. In patients with pulmonary hypertension, new chest pain, acute chest pain, or cardiogenic shock should raise the suspicion of pulmonary artery dissection, which can result in sudden death.
\end{abstract}

Keywords: Hypertension, pulmonary; Chest pain; Pulmonary artery.

\section{Resumo}

A dissecção da artéria pulmonar é uma complicação fatal da hipertensão pulmonar de longa duração que se manifesta como dor torácica aguda e lancinante, dispneia progressiva, choque cardiogênico ou morte súbita. Sua incidência é subestimada, e as opções terapêuticas são ainda limitadas. 0 aparecimento de uma dor torácica aguda ou nova, choque cardiogênico ou morte súbita em pacientes portadores de hipertensão pulmonar deve alertar para o diagnóstico de dissecção da artéria pulmonar

Descritores: Hipertensão pulmonar; Dor no peito; Artéria pulmonar.

\section{Introduction}

Pulmonary hypertension is a common syndrome that encompasses a large spectrum of conditions that sometimes have similar pathogenesis, resulting in increased pulmonary vascular resistance, right ventricular overload and dysfunction, and occasionally death. The use of recently approved pulmonary hypertension drugs has led to improved functional capacity and survival of patients with pulmonary hypertension. However, this improved survival creates clinical challenges related to the increased incidence of chronic complications.

\section{Case report}

A 50-year-old male patient diagnosed four years prior with pulmonary hypertension related to schistosomiasis mansoni was admitted to the emergency room of the Federal University of Minas Gerais School of Medicine Hospital das Clínicas, located in the city of Belo Horizonte, Brazil. He presented with new onset, progressively worsening retrosternal chest pain and shortness of breath (functional class 111 pulmonary hypertension according to the World Health Organization). He had been diagnosed with chronic myeloid leukemia seven months prior and had since been on chemotherapy. At admission, transthoracic echocardiography revealed a large non-obstructive central thrombus in the right main pulmonary artery. The right atrium was dilated, and there was mild tricuspid regurgitation, with an estimated pulmonary artery systolic pressure of $63 \mathrm{mmHg}$. He was diagnosed as having in situ thrombosis as a complication of the longstanding pulmonary hypertension. After the possibility of acute coronary syndrome had been excluded, he was discharged on warfarin. He was re-admitted two months later due to progressively worsening, refractory chest pain.

\footnotetext{
* Study carried out in the Department of Pulmonology and Thoracic Surgery, Federal University of Minas Gerais School of Medicine Hospital das Clínicas, Belo Horizonte, Brazil.

Correspondence to: Ricardo de Amorim Corrêa. Rua Abadessa Gertrudes Prado, 77 apto. 802, Vila Paris, CEP 30380-790, Belo Horizonte, MG, Brasil.

Tel. 5531 3293-3910. E-mail: racorrea9@gmail.com

Financial support: None.

Submitted: 2 July 2012. Accepted, after review: 7 December 2012.

${ }^{* *}$ A versão completa em português deste artigo está disponível em www.jornaldepneumologia.com.br
} 
At that time, he had an $\mathrm{SpO}_{2}$ of $96 \%$, and a third heart sound was audible at the lower left parasternal space, accompanied by a murmur of tricuspid regurgitation. The lungs were clear, and the peripheral arterial pulses were symmetric. Laboratory test results were unremarkable, including serum levels of creatine kinase, creatine kinase MB isoenzyme, and troponin. A resting electrocardiogram showed evidence of acute myocardial ischemia in the anterior leads. Transthoracic Doppler echocardiogram revealed a pulmonary artery systolic pressure of $62 \mathrm{mmHg}$, a thrombus in the right pulmonary artery, as in the previous examination, and the presence of a flap at that level that was compatible with pulmonary artery dissection (Figure 1). The diagnosis was confirmed by subsequent CT pulmonary angiography (CTPA; Figure 2). He was transferred to another cardiovascular treatment facility, where attempts were made to correct the defect with an endovascular procedure (via the femoral vein). During the perioperative period, the patient presented with refractory cardiogenic shock. Multiple efforts to resuscitate the patient were unsuccessful, and he died in the operating room.

\section{Discussion}

Aneurysmatic dilatation of the pulmonary artery trunk and its branches is a well-known condition that has been widely reported in the literature. It occurs as a consequence of longstanding pulmonary hypertension, most of the reported cases having been diagnosed at autopsy. ${ }^{(1)}$ The first reports of that condition in patients with schistosomiasis came from Egypt (in patients with schistosomiasis haematobium or mansoni), followed, much later, by reports from Brazil (exclusively in patients with schistosomiasis mansoni). ${ }^{(2,3)}$ Pulmonary artery dissection appears to be related to pulmonary artery dilatation, intimal inflammation, in situ thrombosis, and acute increases in pulmonary pressure. ${ }^{(4,5)}$ Pulmonary artery dilatation and pulmonary aneurysm have been reported to be risk factors that are also associated with other complications. ${ }^{(4)}$

To our knowledge, this is only the second report of a case of pulmonary artery dissection in a patient with schistosomiasis-related pulmonary hypertension, the first such case having been diagnosed at autopsy. (6) Clinically, these cases present with aggravation of previous symptoms of dyspnea and chest pain. The chest pain is typically sharp and can mimic acute

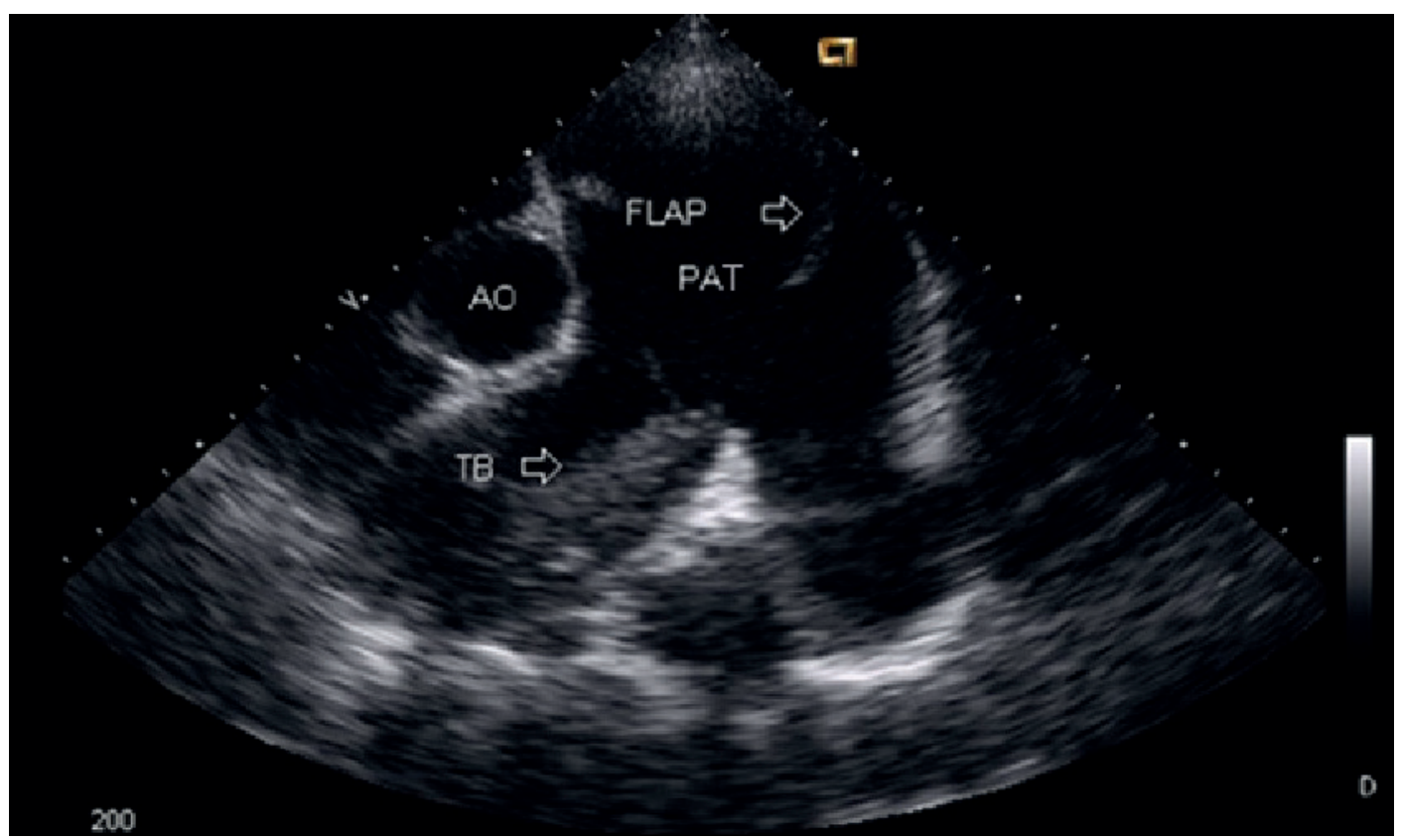

Figure 1 - Transthoracic echocardiogram depicting a thrombus (TB) in the right pulmonary artery and a flap at that level, which is consistent with pulmonary artery dissection. PAT: pulmonary artery trunk; and Ao: aorta. 

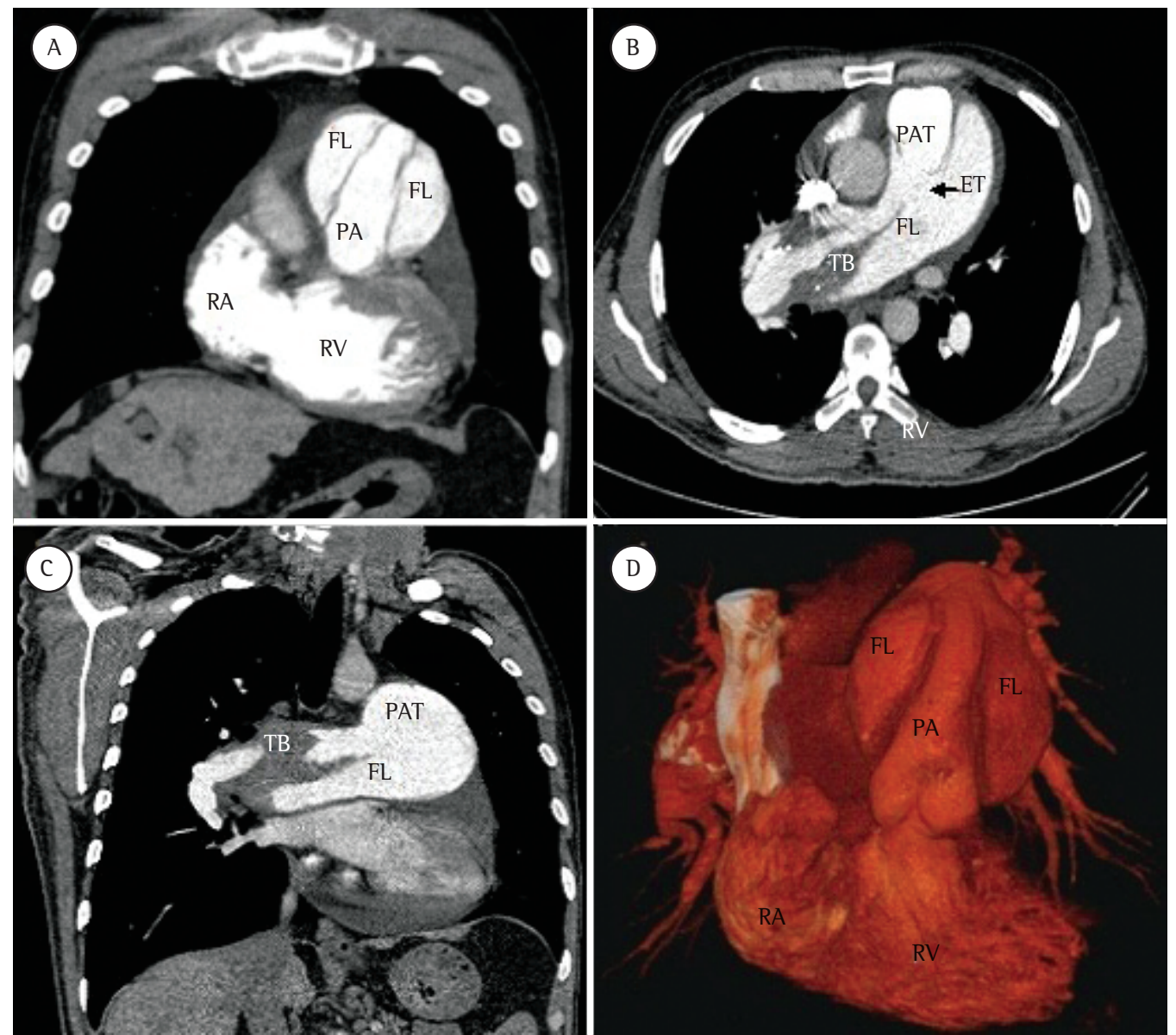

Figure 2 - CT pulmonary angiography scans depicting a flap in the area of dissection in the pulmonary artery trunk (PAT; in A); in situ thrombus (TB) and the entry tear (ET, arrow) into the false lumen (FL; in B); the area of dissection (in $\mathrm{C}$ ); and three-dimensional volume rendering reconstruction (in D). PA: pulmonary artery (lumen); RA: right atrium; and RV: right ventricle.

coronary syndrome or acute aorta dissection. Cyanosis can be present. ${ }^{(7)}$ The diagnosis is often obtained postmortem, because most patients die suddenly due to cardiac tamponade or severe pulmonary bleeding. If the diagnosis is made antemortem, the first finding is the emergence of a flap in the lumen of the dilated pulmonary artery or trunk formed from the intimal layer, denoting the entry tear into the false lumen but rarely an exit, which is the opposite of what is found in cases of aortic dissection. ${ }^{(8)}$ Magnetic resonance imaging or CTPA of the chest can confirm the diagnosis and the associated complications, such as an increase in pulmonary artery dilatation, bloody pleural fluid, and pulmonary opacities.(1) The evolution is usually rupture of the vessel with blood flowing into the mediastinum, pericardium, or lung, because there is no exit from the false lumen. The intimal tear that leads to the dissection occurs at the point of greatest dilatation as a consequence of an increased parietal tension. It has been reported that inflammation due to in situ thrombosis can play a synergistic role in the development of the intimal disruption..$^{(4,9,10)}$

Although it is reasonable to think that the early diagnosis and treatment of pulmonary hypertension would postpone pulmonary artery dissection, there is no confirmatory evidence of that in the literature on this topic, which consists exclusively of reviews and case reports. Therapeutic options are scarce. Surgical repair and heart-lung transplantation are the procedures of choice but have yet to be widely employed, the amount of data available therefore being limited. ${ }^{(7)}$

In patients with pulmonary hypertension, new chest pain, acute chest pain, or cardiogenic shock should raise the suspicion of pulmonary artery dissection, which can result in sudden death. 


\section{References}

1. Moraes MG, Comparato LFL, Madi K. Aneurisma de artéria pulmonar: relato de um caso. Rev Med HSE. 1974;26(2):109-15

2. Zaky HA. Aneurysm of the pulmonary artery due to schistosomiasis. Dis Chest. 1952;21(2):194-204.

3. Santiago JM, Barros J, Rocha LF, Kalil M, Malleta CA, Chuster M. Aneurisma de artéria pulmonar secundário à hipertensão esquistossomótica. Relato de um caso. Arq Bras Cardiol. 1974;27(6):733-6.

4. Degano B, Prevot G, Têtu L, Sitbon O, Simonneau G, Humbert M. Fatal dissection of the pulmonary artery in pulmonary arterial hypertension. Eur Respir Rev. 2009;18(113):181-5.

5. Inayama Y, Nakatani Y, Kitamura H. Pulmonary artery dissection in patients without underlying pulmonary hypertension. Histopathology. 2001;38(5):435-42. Erratum in: Histopathology. 2001;39(5):550.
6. Miziara HL, Filomeno AP, Yunes MA. Dissecting aneurysm of the pulmonary artery, associated with pulmonary schistosomiasis. Report of a case [Article in Portuguese]. Arq Bras Cardiol. 1981;37(2):107-10.

7. Senbaklavaci O, Kaneko Y, Bartunek A, Brunner C, Kurkciyan E, Wunderbaldinger $\mathrm{P}$, et al. Rupture and dissection in pulmonary artery aneurysms: incidence, cause, and treatment--review and case report. J Thorac Cardiovasc Surg. 2001;121(5):1006-8.

8. Song EK, Kolecki P. A case of pulmonary artery dissection diagnosed in the Emergency Department. J Emerg Med. 2002;23(2):155-9.

9. Moser KM, Fedullo PF, Finkbeiner WE, Golden J. Do patients with primary pulmonary hypertension develop extensive central thrombi? Circulation. 1995;91(3):741-5.

10. Andrews R, Colloby P, Hubner PJ. Pulmonary artery dissection in a patient with idiopathic dilatation of the pulmonary artery: a rare cause of sudden cardiac death. Br Heart J. 1993;69(3):268-9.

\section{About the authors}

\section{Ricardo de Amorim Corrêa}

Professor. Department of Pulmonology and Thoracic Surgery, Federal University of Minas Gerais School of Medicine Hospital das Clínicas, Belo Horizonte, Brazil.

\section{Luciana Cristina dos Santos Silva}

Professor. Department of Internal Medicine, Federal University of Minas Gerais School of Medicine, Belo Horizonte, Brazil.

\section{Cláudia Juliana Rezende}

Head. Diagnostic Imaging Center, Hospital Madre Teresa, Belo Horizonte, Brazil.

\section{Rodrigo Castro Bernardes}

Head. Department of Cardiovascular Surgery, Hospital Madre Teresa, Belo Horizonte, Brazil.

\section{Tarciane Aline Prata}

Pulmonologist. Department of Pulmonology and Thoracic Surgery, Federal University of Minas Gerais School of Medicine Hospital das Clínicas, Belo Horizonte, Brazil.

\section{Henrique Lima Silva}

Physician. Department of Internal Medicine, Federal University of Minas Gerais School of Medicine Hospital das Clínicas, Belo Horizonte, Brazil. 